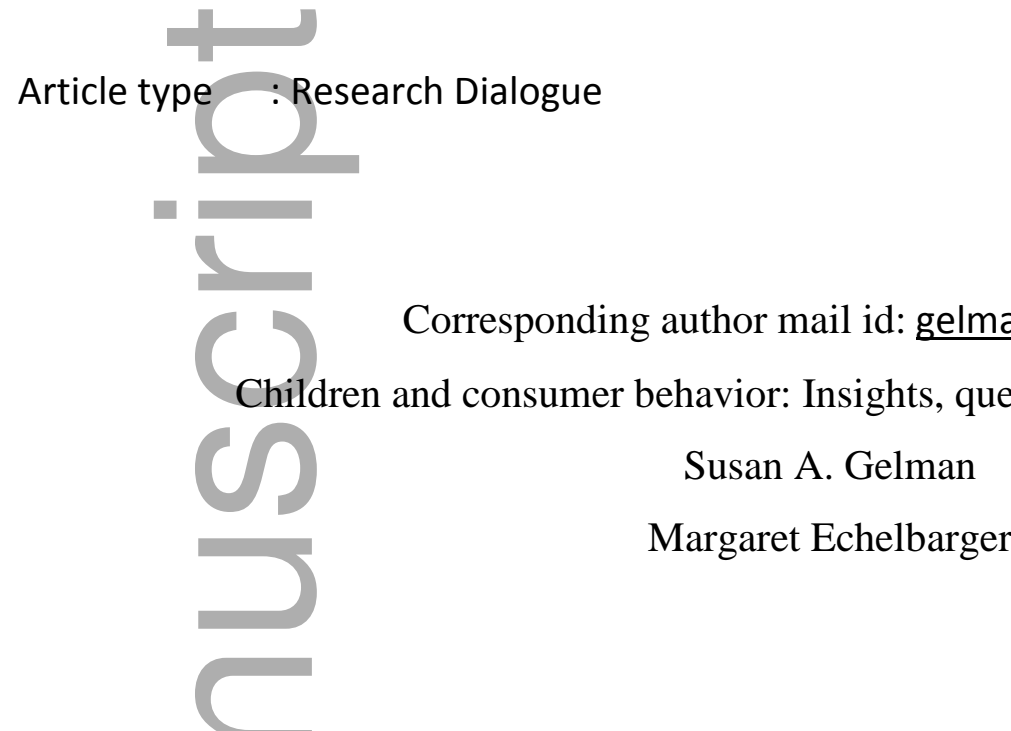

We thank Deborah John, Lan Chaplin, and Daphna Oyserman for their insightful and generous responses. Each commentary seriously takes up the challenge we set forth at the end of our target article - how to link the research on children's concepts of object value to broader issues involving persuasion, including social influences on choices, behaviors, and values. In doing so, they build on our original paper in rich and exciting ways.

John and Chaplin underscore the significance of non-obvious and inferred qualities, broadening these notions beyond the focus of the target article (namely, essentialism and object history) to include an item's symbolic aspects, such as status, prestige, or social meaning. By the teen years, these "hidden" attributes can be central in helping a young person attain their goals. Thus, for example, a middle-schooler may reason that a good way to make friends is to buy products that their peers have, and a high school student may select a North Face logo to illustrate "Who am I?" because it captures her self-perceived personality. Products are not just attractive or functional in their own right, but have layers of social meaning that are core to a person's identity formation, self-presentation, and happiness. John and Chaplin rightly remind us that the full emergence of these connections requires social reasoning capacities that take years to develop. They summarize a number of ingenious studies of children's instrumental valuation This is the author manuscript accepted for publication and has undergone full peer review but has not been through the copyediting, typesetting, pagination and proofreading process, which may lead to differences between this version and the Version of Record. Please cite this article as doi: $\underline{10.1002 / J C P Y .1096}$ 
of objects, revealing robust developmental changes. With age, children become increasingly aware of multiple ways that products and brands can signal important aspects of identity, to the self and to others.

Oyserman focuses on essentialism, and articulates how essentialism of social groups has far-reaching implications for identity-based motivation (IBM) theory. Viewing a goal as linked to one's essence increases a person's motivation to pursue that goal, even in the face of difficulty. At the same time, essentialism can be demotivating, when a goal is viewed as linked to the essence of a group to which one does not belong. Oyserman also underscores the important point that essentialism is a psychological construct and not a metaphysical claim about the world. As such, researchers must take care not to make essentialist assumptions about essentialism itself (e.g., that it is universal, unvarying, or reflects true essences). In this vein, she notes an interesting paradox: "Essentialized identities feel permanent yet small shifts in social context can shift which essentialized identity comes to mind and whether people are likely to accept or counter argue essentialism-based persuasion attempts" (emphases added). In this regard, people (including children) are highly sensitive to cues from social others as to when to essentialize-and when not to. This last point suggests opportunities for reducing the harmful consequences of essentialism, such as stereotyping or prejudice.

\section{Objects and the self}

The target paper is focused on the value of items out in the world that have an existence independent of humans_-such as blankets, paintings, tigers, or tomatoes. In contrast, both commentaries incorporate theories and findings about the self, and specifically people's meaning-making and goals. This move from external objects to internal motivations reflects a central insight: One enduring way we relate to one another is through objects. As humans, our relationships to objects are imbued with social meaning, and our social concepts extend out to objects (Belk, 1988). This can be seen with a vast array of interactions, including gift-giving, bartering, religious ritual, or robbery. Indeed, the folk tendency to disapprove of market-based (utility-maximizing) economic exchanges (also known as "emporiophobia"; Boyer \& Peterson, 2018) arguably reflects the contrast between impersonal, structural systems to manage the exchanges of resources (using money), and those resource exchanges that are local, personal, and relationship-based. Both perspectives are fundamental-even young children at times value resource-maximizing motives, and at times value those that are altruistic (Echelbarger, Gelman, 
\& Kalish, 2018a, 2018b; McGuire et al., 2018). The key point here is that there is a continuous thread linking foundational human object concepts with concepts of the self, but also that an important task of childhood is to acquire culturally-specific norms regarding what is appropriate in different contexts (i.e., when to embrace vs. reject market norms).

Future research can go further in exploring the links among objects, motivation, and the self. We briefly mention three such questions here.

When and why do links among object concepts, motivation, and the self-concept develop? Some researchers have proposed that by 5 years of age children have incorporated objects into their self-concepts (e.g., Diesendruck \& Perez, 2015), due to a basic (universal) human need to have some concrete instantiation of the self. At the same time, there are hints of systematic differences in when these links develop, depending on cultural context. For example, people in more individualistic societies are more likely than those in more collectivist societies to show the endowment effect (Maddux et al., 2010), to place a higher value on items associated with unique individuals (Gjersoe et al., 2014), and to display a preference for scarce items (Kim \& Markus, 1999). An important next step would be to determine if similar patterns of cultural difference hold among children, as this would help speak to the source of these effects. For example, it may be that fundamental differences in the cultural meaning of objects is pervasive from early childhood, indicating that children construct their object concepts largely on the basis of culturally varying input. By contrast, cultural differences may emerge relatively late in development and strengthen with age (Rhodes \& Gelman, 2009). This would indicate which mode of reasoning is the developmental "default", as well as the importance of cultural input in shifting this default. Teasing apart universal and culturally specific influences is one broad research question.

How can different motivational consequences of essentialism be reconciled? On the one hand, goals need to be linked to one's essentialized identity in order to be motivating and pursued, a point that is powerfully demonstrated by Oyserman's program of research. Yet on the other hand, essentializing a trait (viewing it as fixed and determined by nature) can be demotivating and lead to avoidance, after encountering failures or setbacks (e.g., Dweck \& Bempechat, 1983). One example of this comes from developmental research on children's attitudes toward helping. When a child's identity as a helper is essentialized by means of language suggesting that it is a stable trait ("You could be a helper"), children are initially 
motivated to engage in higher levels of prosocial behavior (Bryan et al., 2014). However, this same manipulation backfires if children then encounter a setback (e.g., attempt to help but are unsuccessful) (Foster-Hanson et al., in press). Thus, essentializing an aspect of one's identity is a double-edged sword. Figuring out when and how self-concepts are resilient in the face of difficulties may also change as a function of a person's early experiences.

What is the role of psychological ownership on sustainability? To this point we have focused primarily on tangible objects, yet feelings of ownership can extend beyond objects per se to include natural resources, such as parkland, national forests, or even Earth itself. The implications have significance beyond an individual's functioning, to the health of the environment. To the extent that a person's sense of self is personally invested in the environment, this may increase protective attitudes and reduce exploitation (Liao, Gelman, \& Preston, 2019). An important open question is when in development such attitudes can be cultivated. Early on, children are notoriously focused on local contexts (home, school), and may not consider broader societal issues until adolescence. So it is possible that children's appreciation of sustainability issues would likewise advance only gradually. On the other hand, by 5 years of age, children appreciate that ownership extends to land as well as intangible items such as intellectual property (Goulding \& Friedman, 2018; Shaw \& Olson, 2015; see also Verkuyten, Sierksma, \& Thijs, 2015, with older children), and even elementary school children can be passionate about causes that they see as morally fraught, such as eating meat (Hussar \& Harris, 2010). These findings suggest that efforts to instill a sense of environmental stewardship could potentially start quite young.

\section{What can development tell us?}

As noted in the target article, studying children provides important insights that cannot otherwise be reached. It reveals capacities that are basic to human cognition, and in some cases distinctive to humans (e.g., a tendency toward essentialism). It also reveals mechanisms and components that cannot readily be teased apart when studying adults. For example, John and Chaplin's finding that adolescents, but not younger children, treat brands as markers of identity, suggests that the instrumental value of brands may rest on concepts of the self that emerge over this period.

As another example, consider the finding that adults differ in their emotional attitudes toward saving and spending, with tightwads experiencing too much anticipatory pain of 
spending, and spendthrifts experiencing too little anticipatory pain (Rick, Cryder, \& Loewenstein, 2008). One possibility is that such differences emerge from years of experience handling one's own finances, such that children start out as spendthrifts and only gradually over time do we see some individuals shifting toward tightwaddism. To the contrary, in our own research, we find that young children, too, vary on the tightwad/spendthrift dimension (Smith et al., 2018). We have found that children as young as five years can accurately report on their spending orientation, that these feelings accord with parent reports, and that these feelings have predictive utility (i.e., they predict whether children will spend or save $\$ 1$ we give them; Smith et al., 2018). Thus, experience with money and spending alone cannot explain how these feelings develop - though, without examining these "adult" responses in children, we would be left with an incomplete understanding of their origins. In ongoing work, we seek to test which child- and parent-level factors as associated with children's feelings about spending and saving and whether these feelings change over time.

Childhood is also a critically important point in the lifespan. It is a time when preferences and expectations are established that may persist for years (e.g., brand loyalty; habits that can have lifelong consequences, such as diet, smoking, or drinking; cultural values involving individualism, collectivism, freedom, or self-improvement). The mechanisms underlying these formative effects, and how best to shift these behaviors at different points in life, are complex questions that motivate much important ongoing research (e.g., Bryan et al., 2016; Schulenberg \& Maggs, 2002).

But also, childhood is important because understanding the distinctive limitations and perspectives that children bring can help them to make better decisions-both in childhood, and later as adults. John and Chaplin's commentary is particularly valuable in this respect, as it brings to the forefront the importance of developmental change. Although our target article focused on the early emergence of children's attention to essentialism and object history, this is not to say that either of these concepts is static or unchanging. For example, which categories are essentialized changes with age and experience (see Rhodes \& Mandalaywala, 2017, for review), and as children get older, they increasingly incorporate information about history into their concepts and valuations of objects (Ganea et al., 2007; Gelman et al., 2012, 2015).

At the same time as we acknowledge the importance of developmental change, we also believe that capacities do not emerge de novo later in development, but rather have earlier 
precursors. From 2-3 years of age, children possess a naïve theory of ownership framed in terms of causal principles that connect possessions to permissible actions (Nancekivell et al., in press), including those that may be deeply self-relevant. Even preschoolers view object choices as requiring consistency with their self-concept (e.g., a boy will reject an attractive novel toy as not 'for me' if earlier he heard that it was one that girls really liked; Martin, Eisenbud, \& Rose, 1995), and prefer foods that are modeled by those that they perceive as similar to themselves (Frazier et al., 2012). Furthermore, as noted earlier, an item can be incorporated into a child's self-concept by 5 years of age (Diesendruck \& Perez, 2015). These initial sensitivities to the selfrelevant meaning of items and choices precede children's sensitivity to brands as self-relevant. A rich arena for research in the future is to understand precisely what are those foundational capacities that are found in preschool children, and perhaps even infants, and how they contribute to the developmental progression so elegantly set forth by John and Chaplin. More generally, we cannot understand consumer behavior without a consideration of development considered broadly (within people, communities, and over time).

\section{Integration}

Both John and Chaplin's and Oyserman's contributions beautifully complement the basic research on early concepts by considering the purposes to which these concepts are put. A powerful theme that emerges is the interactive nature of conceptual frameworks and context. The commentaries discuss important elements that interact with essentialism and non-obvious attributes, resulting in consequences for persuasion and motivation. Indeed, this research dialogue reflects the type of conversations and collaborations we wish to see more of as the area of developmental consumer behavior moves forward. In this section, we highlight ways in which both commentaries reflect the types of integration we challenge others to take up, and point to areas where more research is needed.

Oyserman's emphasis on cultural variation in what is essentialized points to the important role of cultural input. Although much research focuses exclusively on either what children know or what adults explicitly teach, we suggest there is an evolved fit between the expectations of the child learner and the implicit cues provided by social others (see also Csibra \& Gergely, 2009). This expectation is grounded in a theoretical and empirical framework in which children are highly sensitive and alert to cues from their environment to signal which categories are meaningful and self-relevant (Gelman, 2009; Rhodes \& Gelman, 2009). Social transmission, 
then, is a powerful tool through which children (and adults) come to learn and reason about the world around them. An important question for the future is which cues or messages (both explicit and implicit) inform this transmission process (Gelman \& Roberts, 2017). Growing evidence suggests that the choices that adults make every day in interactions with children have the potential to nudge children toward a range of different choices (e.g., Chestnut \& Markman, 2018). For this reason, it is critical that researchers carefully consider the multiple influences among children, adults, and their environment across time, which Osyerman's response suggests.

John and Chaplin emphasize that the non-obvious meaning of products and brands requires a framework of thinking about social meaning, including caring about how others perceive the self, and the symbolic meaning of brands, both of which undergo developmental change. We are excited by the possibility of studying this developmental process directly-that is to use short-scale longitudinal methods (also known as 'microgenetic' methods) to probe the mechanisms underlying these changes. For example, it would be fascinating to examine those moments when values shift, as when an item (toy, product, brand, pop artist, or even food) spikes in popularity and spreads through a social group or community. Recent work has developed methodological tools for tracking the cultural transmission processes that lead to spread of ideas across children within a social community, by studying diffusion chains (e.g., Whiten \& Flynn, 2010).

John and Chaplin also note that "the value of products for meeting one's goals are not necessarily inherent in the object, but are shaped by the 'hidden reality' of how the object helps one attain an important goal." We agree wholeheartedly. Nonetheless, one interesting possibility is that children may misconstrue the source of this value. For example, recent work indicates that children and adults alike are prey to an "inherence heuristic" whereby they mistakenly believe that properties that are contingent (e.g., the result of historical or structural forces) are inherent in objects (e.g., orange juice is inherently well-suited to be consumed at breakfast; pink is inherently well-suited to be worn by girls). It would be interesting to test whether a similar sort of bias operates in children's reason about products and brands. For example, when explaining product value, or the choices that people make, do younger children assume that certain brands are inherently worse than others, or (more troubling) that people who use a "lesser" brand do so because they themselves are lesser in some way?

Together, these commentaries exemplify the direction we find most exciting, which is 
bridging basic research on conceptual development in children, with pressing issues regarding motivation and consumer behavior. These two research programs have similar motivations to understand the developing decision-maker. Given the added richness afforded by applying a developmental approach, as observed in their own work, there is increasing need to incorporate both disciplinary approaches, moving forward. Researchers have a unique opportunity to tease apart contributions of experience with other factors associated with consumer behavior, and allow for testing the robustness of theories generated with adult populations to their emergence early in life, as well as changes over the lifespan.

\section{References}

Belk, R. W. (1988). Possessions of the extended self. Journal of Consumer Research, 15(2), 139168.

Boyer, P., \& Peterson, M. B. (2018). Folk-economic beliefs: An evolutionary cognitive model. Behavioral and Brain Sciences, 41, e158.

Bryan, C. J., Master, A., \& Walton, G. M. (2014). "Helping” versus "being a helper": Invoking the self to increase helping in young children. Child Development, 85(5), 1836-1842.

Bryan, C. J., Yeager, D. S., Hinojosa, C. P., Chabot, A., Bergen, H., Kawamura, M., \& Steubing, F. (2016). Harnessing adolescent values to motivate healthier eating. Proceedings of the National Academy of Sciences, 113(39), 10830-10835.

Chestnut, E. K., \& Markman, E. M. (2018). “Girls are as good as boys at math” implies that boys are probably better: A study of expressions of gender equality. Cognitive Science, 42(7), 2229-2249.

Csibra, G., \& Gergely, G. (2009). Natural pedagogy. Trends in Cognitive Sciences, 13(4), 148153.

Diesendruck, G., \& Perez, R. (2015). Toys are me: Children's extension of self to objects. Cognition, 134, 11-20.

Dweck, C. S., \& Bempechat, J. (1983). Children's theories of intelligence: Consequences for learning. In S. Paris, G. Olson, and H. Stevenson (Eds.), Learning and motivation in the classroom (pp. 239-256). Hillsdale, NJ: Erlbaum. 
Echelbarger, M., Gelman, S. A., \& Kalish, C. W. (2018a). Getting what you pay for: Children's use of market norms to regulate exchanges. Child Development. Advance online publication.

Echelbarger, M., Gelman, S. A., \& Kalish, C. W. (2018b). How does “emporiophobia” develop? Behavioral and Brain Sciences, 41, e168.

Flynn, E. G., Laland, K. N., Kendal, R. L., \& Kendal, J. R. (2013). Developmental niche construction. Developmental Science, 16(2), 296-313.

Foster-Hanson, E., Cimpian, A., Leshin, R. A., \& Rhodes, M. (in press). Asking children to "be helpers" can backfire after setbacks. Child Development.

Frazier, B. N., Gelman, S. A., Kaciroti, N., Russell, J. W., \& Lumeng, J. C. (2012). I'll have what she's having: The impact of model characteristics on children's food choices. Developmental Science, 15(1), 87-98.

Ganea, P. A., Shutts, K., Spelke, E. S., \& DeLoache, J. S. (2007). Thinking of things unseen: Infants' use of language to update mental representations. Psychological Science, 18, 734-739.

Gelman, S. A. (2009). Learning from others: Children's construction of concepts. Annual Review of Psychology, 60, 115-140.

Gelman, S. A., Manczak, E. M., \& Noles, N. S. (2012). The nonobvious basis of ownership: Preschool children trace the history and value of owned objects. Child Development, 83(5), 1732-1747.

Gelman, S. A., Frazier, B. N., Noles, N. S., Manczak, E. M., \& Stilwell, S. M. (2015). How much are Harry Potter's glasses worth? Children's monetary evaluation of authentic objects. Journal of Cognition and Development, 16(1), 97-117.

Gelman, S. A., \& Roberts, S. O. (2017). How language shapes the cultural inheritance of categories. Proceedings of the National Academy of Sciences, 114(30), 7900-7907.

Gjersoe, N. L., Newman, G. E., Chituc, V., \& Hood, B. (2014). Individualism and the extendedself: Cross-cultural differences in the valuation of authentic objects. PloS One, $9(3)$, e90787.

Goulding, B. W., \& Friedman, O. (2018). The development of territory-based inferences of ownership. Cognition, 177, 142-149. 
Hussar, K. M., \& Harris, P. L. (2010). Children who choose not to eat meat: A study of early moral decision-making. Social Development, 19(3), 627-641.

Liao, J. D., Gelman, S. A., \& Preston, S. D. (2019). This land is my land: Psychological ownership, but not legal ownership, increases protectiveness for the natural world. Unpublished ms., University of Michigan.

Kim, H., \& Markus, H. R. (1999). Deviance or uniqueness, harmony or conformity? A cultural analysis. Journal of Personality and Social Psychology, 77(4), 785-800.

Maddux, W. W., Yang, H., Falk, C., Adam, H., Adair, W., Endo, Y., ... \& Heine, S. J. (2010). For whom is parting with possessions more painful? Cultural differences in the endowment effect. Psychological Science, 21(12), 1910-1917.

Martin, C. L., Eisenbud, L., \& Rose, H. (1995). Children's gender-based reasoning about toys. Child Development, 66(5), 1453-1471.

McGuire, L., Elenbaas, L., Killen, M., \& Rutland, A. (2018). The role of in-group norms and group status in children's and adolescents' decisions to rectify resource inequalities. British Journal of Developmental Psychology. Advance online publication.

Nancekivell, S. E., Friedman, O., \& Gelman, S. A. (in press). Ownership matters: People possess a naive theory of ownership. Trends in Cognitive Sciences.

Rhodes, M., \& Gelman, S. A. (2009). A developmental examination of the conceptual structure of animal, artifact, and human social categories across two cultural contexts. Cognitive Psychology, 59(3), 244-274.

Rhodes, M., \& Mandalaywala, T. M. (2017). The development and developmental consequences of social essentialism. Wiley Interdisciplinary Reviews: Cognitive Science, 8(4), e1437.

Rick, S. I., Cryder, C. E., \& Lowenstein, G. (2008). Tightwads and spendthrifts. Journal of Consumer Research, 34(6), 767-782.

Schulenberg, J. E., \& Maggs, J. L. (2002). A developmental perspective on alcohol use and heavy drinking during adolescence and the transition to young adulthood. Journal of Studies on Alcohol and Drugs, (14), 54-70.

Shaw, A., \& Olson, K. (2015). Whose idea is it anyway? The importance of reputation in acknowledgement. Developmental Science, 18, 502-509. 
Smith, C. E., Echelbarger, M., Gelman, S. A., \& Rick, S. I. (2018). Spendthrifts and tightwads in childhood: Feelings about spending predict children's financial decision making. Journal of Beha vioral Decision Making, 31(3), 446-460.

Verkuyten, M., Sierksma, J., \& Thijs, J. (2015). First arrival and owning the land: How children reason about ownership of territory. Journal of Environmental Psychology, 41, 58-64.

Whiten, A., \& Flynn, E. (2010). The transmission and evolution of experimental microcultures in groups of young children. Developmental Psychology, 46(6), 1694-1709.

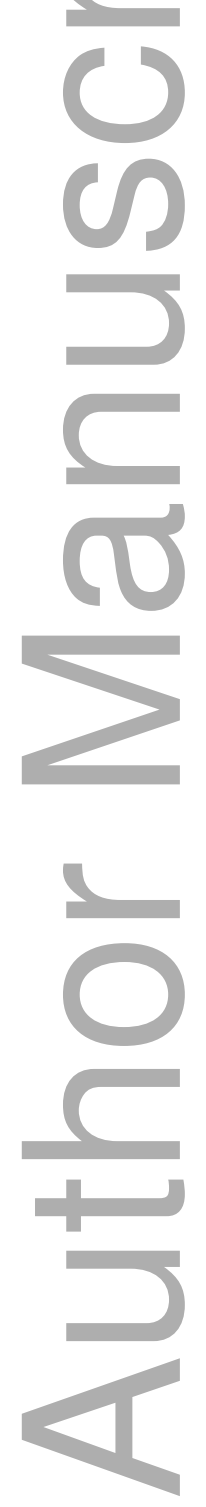

This article is protected by copyright. All rights reserved 